\section{HYDATID DISEASE IN KUWAIT}

\author{
BY \\ ALY EL GAZZAR, M.Ch. \\ Senior Surgeon, Annexe Hospital, Kuwait; \\ Lecturer in Surgery, Cairo University \\ AND

\section{W. A. MCCREADIE, L.R.C.P.\&S.Ed.} \\ L.R.F.P.S. \\ Chief Medical Officer, American Independent \\ Oil Company, Kuwait
}

Hydatid disease is caused by the cestode Echinococcus granulosus and is an example of those diseases that are naturally transmitted between animals and man and which have been labelled zoonoses by the World Health Organization. The reservoir or definitive carnivorous hosts are dogs, wolves, jackals, foxes, and domestic cats, which ingest the cysts present in the carcasses and offal of the intermediate herbivorous hosts-sheep, cattle, camels, goats, horses, and pigs. Man is an accidental intermediate host.

The disease has not been thought of sufficient significance in the Persian Gulf States to allow the area to be recorded as a hydatid area. Palestine, Syria, and Lebanon have been recorded as areas in which there is a high incidence of hydatid disease in man, whereas Egypt and the south and west of the Arabian Peninsula are areas of low incidence.

\section{Incidence}

In spite of the number of patients seen with this disease in Kuwait it was not until investigations were begun that its significance was recognized (El Gazzar, 1961). By checking the operation registers and the hospital records it was found that 51 proved cases of hydatid disease had been admitted to hospitals in the State from 1956 to 1960 inclusive. Prior to 1956 the records system was not wholly satisfactory. Patients seen in clinics (health centres) where the diagnosis of hydatid disease had been made have not been included.

The accompanying Table shows the number of patients suffering from proved hydatid disease admitted to hospitals in Kuwait between 1956 and 1960. It also shows the number of patients who underwent treatment for this disease. A small number of patients did not undergo operation, in some cases because the patients refused surgical intervention.

\begin{tabular}{|c|c|c|c|c|c|c|c|}
\hline \multirow{2}{*}{ Year } & \multirow{2}{*}{$\begin{array}{c}\text { Total } \\
\text { Admitted }\end{array}$} & \multicolumn{2}{|c|}{$\begin{array}{c}\text { Kuwait } \\
\text { State Hospitals }\end{array}$} & \multicolumn{2}{|c|}{$\underset{\text { Mission Hospital }}{\text { American }}$} & \multicolumn{2}{|c|}{$\begin{array}{c}\text { Kuwait Oil } \\
\text { Company Hospital }\end{array}$} \\
\hline & & No. & Operated & No. & Operated & No. & Operated \\
\hline $\begin{array}{l}1956 \\
1957 \\
1958 \\
1959 \\
1960\end{array}$ & $\begin{array}{r}6 \\
6 \\
5 \\
10 \\
24\end{array}$ & $\begin{array}{r}6 \\
6 \\
4 \\
8 \\
22\end{array}$ & $\begin{array}{r}5 \\
5 \\
4 \\
7 \\
20\end{array}$ & $\bar{\Xi}$ & $\bar{\Xi}$ & $\begin{array}{l}\overline{7} \\
1 \\
1\end{array}$ & $\begin{array}{c}\overline{7} \\
\frac{1}{2} \\
1\end{array}$ \\
\hline Total & 51 & 46 & 41 & 1 & 1 & 4 & 4 \\
\hline
\end{tabular}

\section{Diagnosis}

The diagnosis was made in all cases on clinical, radiological, and laboratory findings. Hydatid cysts situated on the anterior surface and on the lower border of the liver can be diagnosed clinically without difficulty.
The radiological appearances of hydatid cysts in the lungs are usually distinctive (Fig. 1). In a straight $x$-ray film of the abdomen the fine edge of a cyst in the liver can often be seen. The Casoni intradermal test was used, but with this test a negative result did not exclude hydatid disease. In our cases it was found at times to be negative, particularly where there had been longstanding hydatid disease with superadded infection. An eosinophil count was of little diagnostic value, as other intestinal parasites are very common in this part of the world. The complementfixation test was not used.

Exploratory puncture is contraindicated, but in three cases this was done. One case presented with an abscess in the region of the elbow which on aspiration pro-

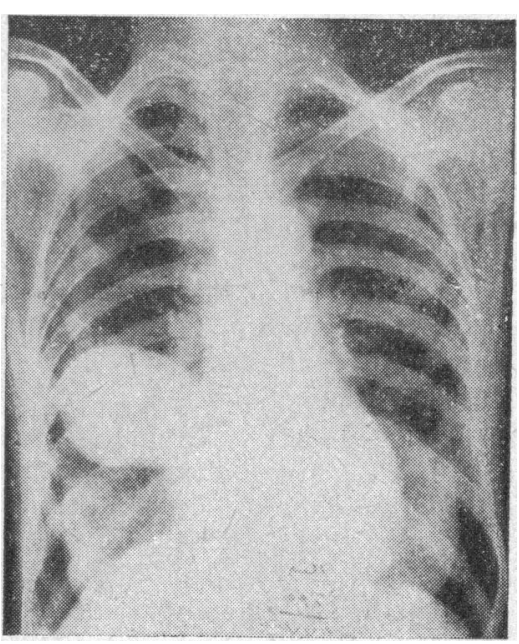

Fig. 1.- Hydatid cyst of lung. duced a seropurulent fluid; on incision this proved to be a hydatid cyst. The second case was diagnosed as a pleural effusion, and 3 pints (1.7 litres) of clear fluid was aspirated which, after centrifugation, showed hydatid scolices on microscopical examination. Fortunately no complications followed this procedure. The third case presented with a swelling in the lumbar region that was diagnosed as a cold abscess. Aspiration failed to produce fluid, and at operation a hydatid cyst containing a large number of vesicles stuck together by thick gelatinous fluid was found.

The sites of hydatid disease were: liver, 23 ; spleen, 3 ; lung, 7 ; bone, 2 ; muscles, 6 ; breast, 1 ; peritoneum, 6 ; ovary, 1 ; kidney, 1 ; intraorbital, 1.

\section{Treatment}

The treatment of choice in aged patients and in those with calcified cysts (Fig. 2) is to leave them alone, provided there is no secondary infection or other symptoms, when the prognosis is good. In the absence of symptoms deep-seated lung cysts may not require surgical intervention, but they must be followed up by annual $x$-ray examinations. In two of our cases the hydatid cyst in the lung was coughed up and they were cured spontaneously. Excision of the cyst, complete with its pericyst, can be carried out only if the cyst is pedunculated or is easily accessible, as in muscles (Figs. 3 and 4) and mesentery. Removal of the organ involved by the cyst was performed in other cases-for example, splenectomy, nephrectomy, oophorectomy, and lobectomy.

Hydatid cyst of the liver should be operated on to avoid its possible complications. We have found black packs most useful in this operation for the detection of escaping hydatid elements; these show up very well on this background. Aspiration to reduce the tension inside the cyst is carried out and $4 \%$ formalin injected and left for a few minutes to kill the scolices. Formalin $20 \%$ or $40 \%$ should not be used as it has a necrotizing and hardening effect on the tissues which we have found 
to delay healing. The cyst is then opened and the contents are surked out or removed with sponge-holding forceps. If the contents are thick an ordinary sterile tablespoon is useful. The germinal membrane should be removed. Packs moistened with $4 \%$ formalin may be left in the cavity for a few minutes, after which it

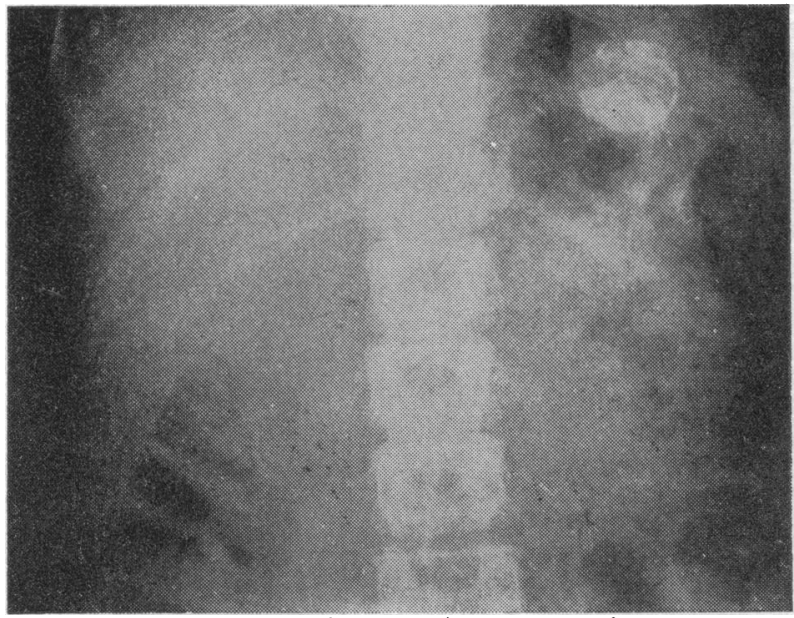

Fig. 2.-Calcified hydatid cyst of spleen.

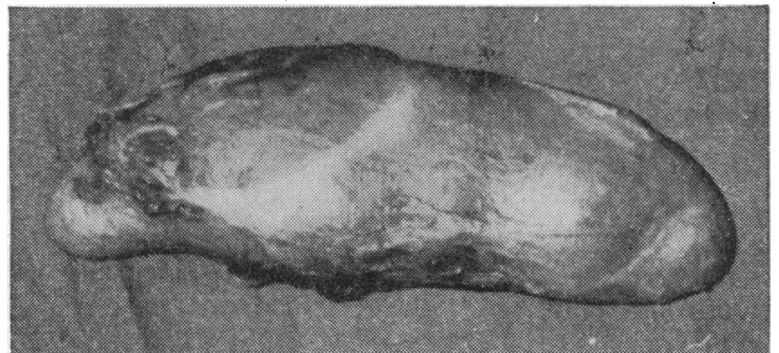

Fig. 3.-Hydatid cyst removed from the sacrospinalis muscle.

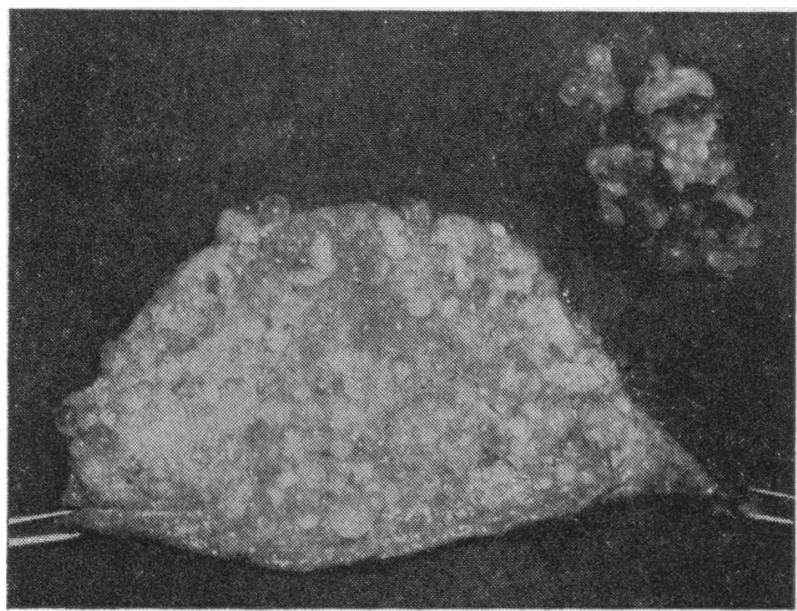

Fig. 4.-Same cyst as in Fig. 3, opened to show daughter cysts and inspissated material.

is washed with saline to remove the formalin and any remaining hydatid debris. The cyst wall is fixed to the wound or marsupialized, and a drainage-tube is inserted. If a hydatid cyst ruptures into the peritoneum with widespread dissemination of scolices peritonitis may follow or the scolices may die and can later be found as dots on the peritoneum, giving the appearance of tuberculous nodules.

In general the prognosis in hydatid disease is good in the absence of infection, the operative mortality in non-infected patients is negligible, and the results of operation are excellent. In the presence of infection the operative mortality rises sharply.

\section{Discussion}

The majority of the patients are immigrants from other countries-Iraq, Iran, Saudi Arabia, and Jordanonly five patients in this series being Kuwaitis. Many of these immigrants are Bedouins. The life of the Bedouins is nomadic and they travel from place to place in search of food and water for their flocks. They and their animals-sheep, camels, goats, and dogs-use the same source of water for drinking and other purposes and thus their mode of life is ideal for the transmission of hydatid disease to man. The 1957 census in Kuwait gave the total population as 206,000 , of which 114,000 were Kuwaitis, and the 1961 census showed the total population to be 321,000 . This indicates the large number of Arabs of the surrounding States who emigrate to Kuwait.

In the five years 1956-60 there were in Kuwait 51 admissions of proved cases of hydatid disease, an average of approximately 10 a year. The population of Kuwait averaged 260,000 for the years $1956-60$, so that in theory the incidence of hydatid disease is approximately 1 in 26,000 . In fact, the incidence is very much less, as previously infected immigrants have come to the State with the disease; and, furthermore, because of the entirely free health service which the State offers to all persons in it, patients come from all countries in the Arabian Peninsula and from Iraq and Iran for treatment and leave when the treatment is completed. Thus the population served by the Kuwait Health Service is far greater than the population of the State. Kuwait is an example of a country in which a disease that is not endemic has become of definite surgical significance because of the free health service.

The prevention of hydatid disease consists essentially in breaking the link between the dog and the sheep, thereby disrupting the life-cycle of this cestode. The life of the tapeworm is about six months after maturity, so that the dog, unless reinfected, will become free of the parasite in about eight months (W.H.O./F.A.O., 1959). Dogs must be denied access to carcasses and offal and should be given only properly cooked meat; and regular deworming with arecoline bromide, in the dosage of $4 \mathrm{mg}$. $/ \mathrm{kg}$. body weight, must be undertaken. In hydatid areas the accidental involvement of humans, particularly children, can be prevented if they are taught not to fondle dogs, and other measures include the thorough cleansing of all vegetables and fruits and utensils, and the practice of impeccable personal hygiene. Extensive propaganda is required so that, with the co-operation of farmers, dog-owners, and interested societies, it becomes a matter of pride that no animals can be found to have hydatid disease on routine inspections.

\section{Summary}

A review of the records of the patients admitted to hospitals in Kuwait with a proved diagnosis of hydatid disease from 1956 to 1960 inclusive has shown that hydatid disease is of definite surgical significance now.

An account of the methods used in diagnosis is given. It is noted that the Casoni intradermal test is often negative in the presence of superadded infection and that the eosinophil count is of no value in this area, as intestinal parasites are very common. 
The methods of treatment are discussed and particular reference is made to hydatid disease of the liver. The advantages of using black packs at operation are emphasized. It is suspected that the use of solutions of formalin in concentrations greater than $4 \%$ is a cause of delayed healing post-operatively.

The mode of spread of the disease among the Bedouins in relation to their environment is discussed.

Kuwait has not previously been recorded as a hydatid area, and the reasons for the disease being found here now are purely economic. The influx of previously infected persons into the State is mainly due to the completely free health service and to the paucity of medical services in the surrounding Arab States. It is also due to the prosperity in Kuwait, which attracts immigrants as work is easily obtainable.

It is emphasized that the incidence figures give a false picture because the population served by the Kuwait Health Service is far greater than the population of the State.

The method of prevention of hydatid disease in animals and man is discussed in detail.

We thank all the doctors who were of assistance to us in the examination of the records; Major J. M. Adam, R.A.M.C., for his constructive criticism; and the Chief Medical Officer, Mr. E. Parry, for permission to publish the article.

\section{REFERENCES}

El Gazzar, A. (1961). Arab Medical Congress, Cairo.

W.H.O./F.A.O. (1959). Joint Expert Committee on Zoonoses. 2nd Report. F.A.O. Agricultural Study No. 47.

\footnotetext{
"In more recent years the great advance [in methods of treating leprosy] has in many countries begun to win the confidence of the people. Where formerly the disease remained hidden in fear and prejudice, now more and more sufferers in need of treatment come forward to seek for themselves the benefits which new drugs and new orthopaedic surgery are said to confer. The matter is indeed blazed abroad, and patients flock in 'from every quarter,' sometimes to the embarrassment of medical workers, whose resources are often strained to the limit. The record of the Mission to Lepers' work in 1961 offers an excellent example of this notable increase, the way it tends to develop, and the effort that is made to meet it. On January 30 there was opened a new out-patients' treatment centre at a place called Barabanki, about sixty miles from the Faizabad Leprosy Hospital in Uttar Pradesh, North India. This is a development of the work of the Faizabad Home, which was opened in 1938 by H.E. Sir Maurice G. Hallett, at that time Governor of the United Provinces and now the Honorary Treasurer of the Mission. The scheme was launched by Mr. A. Donald Miller, then Secretary for India, in response to an appeal from local authorities whose main object at that time was to get off the streets the 'leper beggars' who infested Ajodhya, a famous centre for Hindu pilgrims and the reputed birthplace of Ram. It was not thought that there was much leprosy in the Faizabad area. 'Get rid of these beggars, who come from other parts of India, and our problem is solved,' they said. But when Dr. P. J. Chandy began to develop his medical work the news spread throughout the whole area and soon patients were coming from many villages all over the Faizabad civil district, and from far beyond its boundaries. Year by year this process went on, until it became clear that Faizabad itself could no longer cope with the greatly increased flood of out-patients. So the Barabanki treatment centre was built with help from local sources, from the Central Government and the Government of Uttar Pradesh, and from the Mission to Lepers." (From Every Quarter, 1961, Mission to Lepers.)
}

\section{HYDATID DISEASE IN THE POSTERIOR FOSSA}

BY

\section{J. D. CARROLL, M.D.}

Senior Registrar, Department of Neurology, King's College Hospital, London; formerly Resident Medical Officer, National Hospital, Queen Square, London

AND

R. G. LASCELLES, M.B., M.R.C.P., D.P.M.

Registrar, Departments of Neurology and Psychological Medicine, St. Thomas's Hospital, London; formerly Assistant House-physician, National Hospital, Queen Square, London

[With Special Plate]

Hydatid disease affecting the brain is uncommon in this country and its presence in the posterior fossa is a comparative rarity. We are therefore reporting two cases from Malta and Cyprus which were admitted recently to the National Hospital. The diagnosis was established at operation and confirmed by histological study.

One of the first successful posterior fossa craniotomies was performed in 1889 by Maunsell, of Dunedin, when he operated on a subtentorial cyst, at that time thought to be a hydatid, in an 18-year-old youth. Since then many accounts of hydatid disease have appeared in the literature, the largest series being those of Dévé (1913) and Barnett (1943). In the series reported by Dévé $(2,727$ cases $)$ the incidence of cerebral involvement was $1.4 \%$ and in that of Barnett $(1,617$ cases) it was as low at $0.5 \%$. This low incidence of involvement of the central nervous system can be explained by the fact that the larvae have difficulty in passing through the capillary filters of the liver and lung. However, in New Zealand it is said that $1 \%$ of all space-occupying intracranial lesions are hydatid cysts, and the incidence may even be higher if only those under the age of 21 are considered (Robinson, 1960). In view of this possibility cerebral hydatid disease is always seriously entertained if a child presents with symptoms suggestive of such a space-occupying lesion.

In the brain the commonest sites for hydatid disease would appear to be the parieto-occipital and temporal regions (Valentino, 1959). It usually occurs in the form of a single cyst about $5 \mathrm{~cm}$. or more in diameter, multiple cysts being extremely rare. The response of the surrounding brain to the presence of the cyst is minimal, and although there is some gliosis a perfect plane of cleavage remains between the cyst and the brain.

\section{Case 1}

The patient, a boy of 6, was referred by Professor Zammit Maempel, of St. Luke's Hospital, Malta. He had been in good health until March, 1959, when he developed an influenza-like illness consisting of a high temperature. malaise, unproductive cough, and a watery discharge from the nose. The acute symptoms lasted a week, and during the following week there was a complete recovery. On April 9 he began to vomit, and this continued for a month, occurring every second or third day and usually on waking in the mornings. The vomiting was associated with severe retro-orbital headaches, photophobia, and irritability. In the early part of May he began to experience obscurations of vision lasting seconds at a time and not associated with change of position. The visual disturbances continued for a month. On his admission to hospital in July all his 